\title{
Structural and Infrared Spectroscopy of Polyvinylpyrrolidone/Multi- walled Carbon Nanotubes Nanocomposite
}

\author{
Shahad M. Omran ${ }^{1 a^{*}}$, Estabraq T. Abdullah ${ }^{1 b}$, Omar A. Al-Zuhairi ${ }^{2 c}$ \\ ${ }^{1}$ Department of Physics, College of Sciences, University of Baghdad, Baghdad, Iraq \\ ${ }^{2}$ Nanotechnology Research Center, Department of Physics, Faculty of Science and Mathematics, \\ Universiti Pendidikan Sultan Idris, 35900 TanjungMalim, Perak, Malaysia \\ bEmail: estabraqtaib@sc.uobaghdad.edu.iq, ${ }^{\mathrm{c}}$ E-mail: omaralkaissy@ gmail.com \\ $\mathrm{a}^{*}$ Corresponding author: shahadmahmed767@gmail.com
}

\begin{abstract}
In this work, polyvinylpyrrolidone (PVP)/ Multi-walled carbon nanotubes (MWCNTs) nanocomposites were prepared with two concentrations of MWCNTs by casting method. Morphological, structural characteristics and electrical properties were investigated. The state of MWCNTs dispersion in a PVP matrix was indicated by Field Effect-Scanning Electron Microscopy (FESEM) which showed a uniform dispersion of MWCNTs within the PVP matrix. X-ray Diffraction (XRD) indicate strong bonding of carbonyl groups of PVP composite chains with MWCNTs. Fourier transfer infrared (FTIR) studies shows characteristics of various stretching and bending vibration bands, as well as shifts in some band locations and intensity changes in others. Hall effect was studied to test the type of charge carriers which was shown to be P-type. The electrical conductivity was shown increased for the pure PVP and pure MWCNT from $\left(2.047 \times 10^{-5}\right)(\Omega . \mathrm{cm})^{-1}$ and $\left(3.683 \times 10^{1}\right)(\Omega . \mathrm{cm})^{-1}$ to $\left(2.51 \times 10^{2}\right.$ and $\left.2.36 \times 10^{2}\right)(\Omega . \mathrm{cm})^{-1}$ for both concentrations of nanocomposites, which indicate the conductivity was enhancement by using the carbon nanotubes.
\end{abstract}

Article info.

Keywords:

polyvinylpyrrolidone, Multi-walled carbon, nanotubes, structural properties, Hall Effect.

Article history:

Received: Jul. 8, 2021

Accepted: Sep. 19, 2021

Published: Dec.01,2021

\section{Introduction}

Carbon nanotubes (CNTs) have captivated the interest of researchers and scientists since Ijiman discovered them due to their extraordinary optical, electrical, thermal, and mechanical properties. Theyhave a wide range of applications such as supercapacitors[1], transistors [2], Schottky contacts [3], solar cells [4], gas sensors [5].

Polymer composites are most attractive to be used with carbon nanotubes since the result has many interesting properties[6,7]. However, it is so difficult to get ahomogeneoussolution of polymer and CNTs. Polyvinylpyrrolidone (PVP) is soluble in water and in many polar solvents such as ethanol which make it easy to be synthesized $[8,9]$. PVP is good ina stable environment, of moderate electrical conductivity, high dielectric strength and with good charge storage capacity. Many studies have investigated the effect of MWCNTs system on the polymeric composites. The results show an enhancement in the mechanical, electrical, thermal and optical properties [10-12], and has many important applications in growing pharmaceutical, biomedical, electronic and optical applications [11, 12].

In this work, casting method was used to prepare the PVP/MWCNTs nanocomposite with two different concentrations of MWCNTs: $0.002 \mathrm{wt} \%$ and $0.005 \mathrm{wt} \%$. FESEM, XRD and FTIR were employed to study its structural properties. Also, the Hall Effect was investigated. 


\section{Experimental work}

\subsection{Materials}

Polyvinylepyroldine (PVP-K30) was supplied by central drug house LTD, with an average molecular weight $\mathrm{M}_{\mathrm{w}}=40000 \mathrm{~g} / \mathrm{mol}$. Multi-walled carbon nanotubes (MWCNTs) have outer diameter 13-18nm with length $\sim 1-12 \mu \mathrm{m}$, and purity $>99 \mathrm{wt}$. $\%$ were purchased from Neutrino.

\subsection{Samples preparation}

The casting solution method was used in this work. First, $4 \mathrm{mg} / \mathrm{ml}$ PVP was dissolved in $50 \mathrm{ml}$ of ethanol and mixed with a magnetic stirrer for 30min. then the solution was sonicated for $30 \mathrm{~min}$. Meanwhile, two concentrations of MWCNTs were dispersed in $50 \mathrm{ml}$ of ethanol stirred for about 24 hours at room temperature. The PVP solution and the MWCNTs were mixed together with a magnetic stirrer for about 48 hours. The last step, the mixtures were kept in the ultrasonic bath for 2 hours in order to obtain homogenous solutions.

\subsection{Characterization}

Field Effect-Scanning Electron Microscope (FESEM) images were obtained with a field emission scanning electron microscope (Quanta FEG-250 SEM) operating at an acceleration voltage of $3 \mathrm{kV}$. The X-ray diffraction patterns were studied usingShimadzu model XRD-6000, theBragg's angle range of $5^{\circ} \leq 2 \theta \geq 60^{\circ}$ and $\mathrm{Cu}$ Karadiationof wavelength $\lambda=1.5406$ Åwith scanning speed of $5 \% \mathrm{~min}$.Shimadzu 8400 FTIR spectroscope was used torecord the FTIR spectra of the fabricated composite filmsin the wave number range $400-4000 \mathrm{~cm}^{-1}$ with a resolutionof $4 \mathrm{~cm}^{-1}$.

\section{Results and discussion}

The FESEM was used to study the surface morphology of pure PVP, pure MWCNTs and its nanocomposites. The results showed a uniform dispersion of MWCNTs within the PVP matrix, as shows in Fig.1. This can be attributed to the good compatibility between the MWCNTs and the polymer chains of PVP. Although at the high concentration of the MWCNTs $(0.005 \mathrm{wt} . \%)$, an aggregation and local irregularities were observed which can be attributed to the MWCNTs nature.
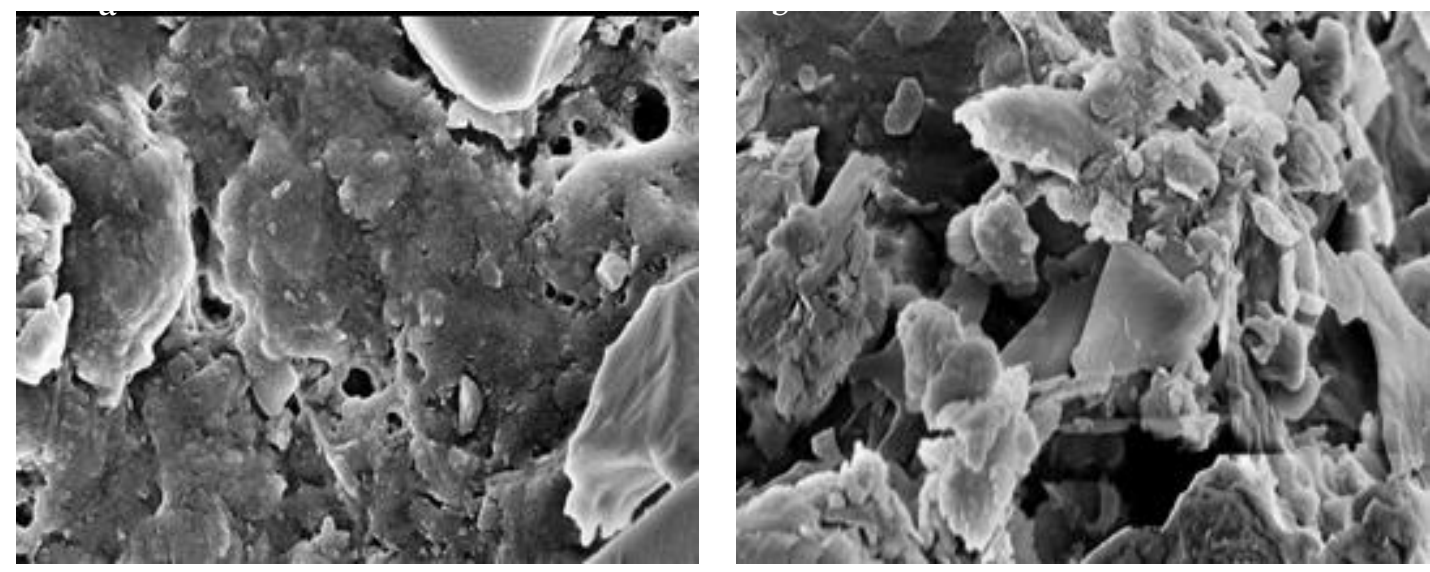

Figure 1: FESEM images for: a) $0.002 w t \%$ and b) $0.005 w t \%$ PVP/MWCNT nanocomposite.

The molecular interaction between PVP and MWCNTs in the nanocomposites was characterized by the XRD technique. Fig.2shows the XRD patterns of pure PVP, 
pure MWCNTs and their nanocomposites. For pure PVP,the mean peaks werelocated at $2 \theta=11,21$ it shows very broad diffraction peaks. These peaks indicate the amorphous nature of the polymer.This result agrees with that of Zidan et al.[13]. For pure MWCNTs, its peaks are at $2 \theta=26.15$ corresponding to $(020)$ crystal plane. This result agrees with that of Abdullah et al. [14]. For the nanocomposites, the peak intensity at $2 \theta=26.15$ becomes sharp and of higher intensity. This indicates that the interaction between MWCNTs and PVP leads to an increase in the inter-molecular interactions between the blend chains [15]. Because of its amorphous form, it has a higher ionic diffusivity, resulting in enhanced ionic conductivity.

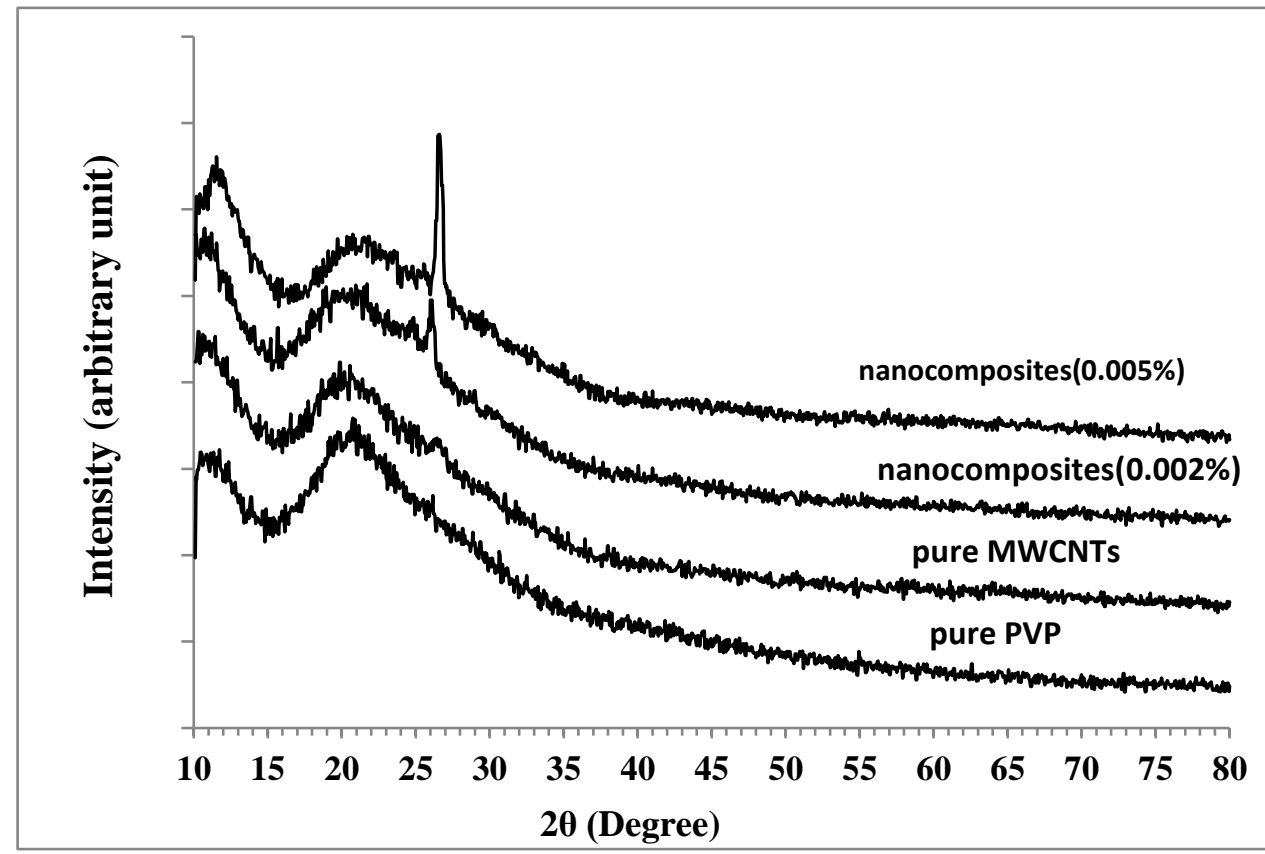

Figure2: XRD patterns of all samples forpure PVP, pure MWCNTs and their nanocomposites

The purpose of FTIR spectroscopy is to examine multi-component functional groups to provide helpful information about the mechanism of interaction and to measure the content of the material phase in a variety of bond types found in all samples. Fig.3 shows the FTIR spectra of the pure PVP, pure MWCNTs and their nanocomposites spectra, they show characteristics of various stretching and bending vibration bands, as well as shifts in some band locations andintensity changes in others. The peaks at: $3377.61 \mathrm{~cm}^{-1}$ corresponds to $\mathrm{OH}$ stretching; $2954.95 \mathrm{~cm}^{-1}$ corresponds to $\mathrm{C}-\mathrm{H}$ stretching; $1514.12 \mathrm{~cm}^{-1}$ corresponds to characteristic vibration of $\mathrm{C}=\mathrm{N}$ (pyridine ring): $1514.12 \mathrm{~cm}^{-1}$ and $1224.80 \mathrm{~cm}^{-1}$ represent the characteristic vibration of $\mathrm{C}=\mathrm{N}$ (pyridine ring) and C-C stretching and/or $\mathrm{CH}_{2}$ deformation, respectively. The results are in good agreement with that of Alibe et al.[11]. FTIR spectrum for the PVP/MWCNT nanocomposites show that the intensity of the peaks has decreased due to the existence of MWCNTs. The broad peak at $3477 \mathrm{~cm}^{-1}$ is due to $\mathrm{OH}$ stretching vibration of the hydroxyl groups. Also, the peak at $1654.92 \mathrm{~cm}^{-1}$ has decreased in intensity and became broader. This exhibits the structural changes of PVP after being filled with MWCNTs. The shift of wave number indicates the change in potential energy distribution along the polymeric chain. These results are in good agreement with those of Zidan et al. [13]. 


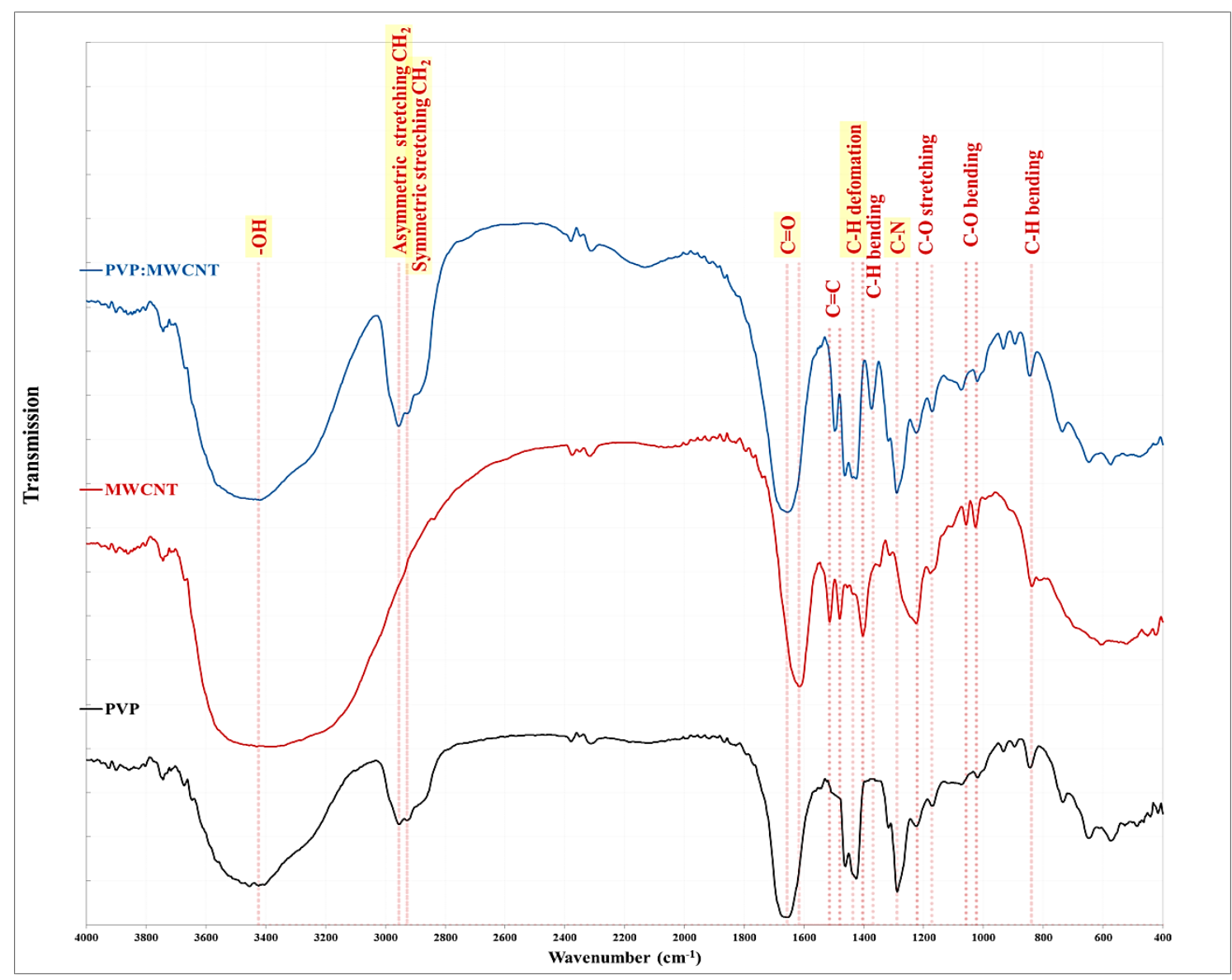

Figure 3: FTIR spectra of pure (PVP, MWCNTs) and their nanocomposite samples.

The Hall measurements of pure PVP, pure MWCNTs and PVP/MWCNTs nanocomposites were studied as shown in Table 1 . The electrical conductivity and carrier mobility were observed to be higher in PVP/MWCNTs nanocomposites as compared with pure samples, which indicates the carrier type was found to be positive for all samples which indicates that holes are the majority charge carriers so the samples are p-type semiconductor. The conductivity and mobility were increased for the two composites by comparing with pure PVP and MWCNTs.

Table1: Hall Effect Parameters.

\begin{tabular}{c|c|c|c|c|c|c}
\hline Samples & $\begin{array}{c}\text { Charge } \\
\text { Concentration } \\
{\left[\mathbf{1} / \mathbf{c m}^{3}\right]}\end{array}$ & $\begin{array}{c}\text { Mobility } \\
{\left[\mathbf{c m}^{2} / \mathbf{V}_{\mathbf{s}}\right]}\end{array}$ & $\begin{array}{c}\text { Resistivity } \\
{[\Omega \mathbf{~ c m}]}\end{array}$ & $\begin{array}{c}\text { Average } \\
\text { Hall } \\
\mathbf{C o e f f i c i e n t} \\
{\left[\mathbf{c m}^{3} / \mathbf{C}\right]}\end{array}$ & $\begin{array}{c}\text { Conductivity } \\
(\mathbf{\Omega} \mathbf{~ c m})^{-\mathbf{1}}\end{array}$ & $\begin{array}{c}\text { Carrier } \\
\text { type }\end{array}$ \\
\hline PVP & $7.381 \times 10^{13}$ & $1.731 \times 10$ & $4.886 \times 10^{4}$ & $8.457 \times 10^{4}$ & $2.047 \times 10^{-5}$ & $\mathrm{P}$ \\
$\begin{array}{c}\text { MWCNTs } \\
\text { PVP+MWCNT } \\
(0.002 \%)\end{array}$ & $1.264 \times 10^{16}$ & $2.753 \times 10^{3}$ & $1.79 \times 10^{-1}$ & $4.937 \times 10^{2}$ & $3.683 \times 10^{1}$ & $\mathrm{P}$ \\
$\begin{array}{c}\text { PVP+MWCNT } \\
(0.005 \%)\end{array}$ & $1.74 \times 10^{17}$ & $7.23 \times 10^{1}$ & $1.67 \times 10^{-1}$ & $8.065 \times 10$ & $8.97 \times 10$ & $\mathrm{P}$ \\
\hline
\end{tabular}




\section{Conclusions}

Ordinary casting techniques were used to create pure PVP, pure MWCNTs, and their nanocomposite samples. FESEM suggests that an entangled network of PVPcoated carbon nanotubes can be easily identified.The establishment of an intermolecular contact between the PVP polymer chain and MWCNTs was revealed by FTIR analysis. The nanocomposites had no notable peaks characterizing MWCNTs, according to the X-ray examination. The semicrystalline character of the examined system was also demonstrated. The Hall measurements indicated p-type carrier for all samples.

\section{Acknowledgments}

The authors wish to express their sincere gratitude for Dr. Osama N. Najifor her Great help during the research.

\section{Conflict of interest}

Authors declare that they have no conflict of interest.

\section{References}

1. Aval L. F., Ghoranneviss M., and Pour G. B. High-performance supercapacitors based on the carbon nanotubes, graphene and graphite nanoparticles electrodes, Heliyon, 2018. 4(11): pp. 1-17.

2. Bishop M.D., Hills G., Srimani T., Lau C., Murphy D., Fuller S., Humes J., Ratkovich A., Nelson M., and Shulaker M.M., Fabrication of carbon nanotube field-effect transistors in commercial silicon manufacturing facilities, Nat. Electron,2020. 3(8): pp. 492-501.

3. Svensson J. and Eleanor Campbell E.B., Schottky barriers in carbon nanotubemetal contacts, J. Aplied Phys, 2011. 110(11): pp. 1-16.

4. Khan D., Ali Z., Asif D., Panjwani M.K andKhan, I., Incorporation of carbon nanotubes in photoactive layer of organic solar cells, Ain Shams Eng. J., 2021. 12(1): pp. 897-900.

5. M.T.S. Chani, K.S. Karimov, and A.M.Asiri, Impedimetric humidity and temperature sensing properties of the graphene-carbon nanotubes-silicone adhesive nanocomposite, J. Mater. Sci. Mater. Electron., 2019. 30(7): pp. 64196429.

6. Enad A.Gh., Abdullah E.T., Hamed, and Hamed M. Gh, Study the Electrical Properties of Carbon Nanotubes/Polyaniline Nanocomposites, Journal of Physics: Conference Series, 2019. 1178(1): pp. 1-8.

7. Itapu B. and Jayatissa A., A Review in Graphene/Polymer Composites, Chem. Sci. Int. J., 2018. 23(3): pp. 1-16.

8. Mergen Ö. B., Umut E., Arda E., andKara S., A comparative study on the AC/DC conductivity, dielectric and optical properties of polystyrene/graphene nanoplatelets (PS/GNP) and multi-walled carbon nanotube (PS/MWCNT) nanocomposites, Polym. Test, 2020.90: pp. 22-37.

9. Quaranta S., Giorcelli M., and Savi P., Graphene and MWCNT Printed Films: Preparation and RF Electrical Properties Study, J. Nanomater., 2019. 2019: pp. 19.

10. Abedi M., Fangueiro R., and Correia A. G., An Effective Method for Hybrid CNT/GNP Dispersion and Its Effects on the Mechanical, Microstructural, Thermal, 
and Electrical Properties of Multifunctional Cementitious Composites, J. Nanomater., 2020. 2020: pp. 1-20.

11. Alibe I.M., Matori K.A., Sidek H-A.A., Yaakob Y., Rashid U.,Alibe A.M., Zaid M.H.M., Nasir S., and Nasir M.M., Effects of polyvinylpyrrolidone on structural and optical properties of willemite semiconductor nanoparticles by polymer thermal treatment method, J. Therm. Anal. Calorim., 2019. 136(6), pp. 2249-2268.

12. Teodorescu M. and Bercea M., Poly(vinylpyrrolidone) - A Versatile Polymer for Biomedical and Beyond Medical Applications,Polym.-Plast.Technol. Eng., 2015. 54(9): pp.923-943.

13. Zidana M., Abdelrazek E.M., Abdelghany A. M., and Tarabiah A. E., Characterization and some physical studies of PVA/PVP filled with MWCNTs., Journal of Materials Research and Technology, 2018.8(1), pp.1-10.

14. Abdullah E. T., Hassan S. M., andAhmed R. S., Electrical Properties of Polyaniline/Functionalized Multi Walled Carbon Nanotubes Nanocomposite, Int. J. Curr. Eng. Technol., 2016. 6(2): pp. 617-621.

15. Fiedler B. and Schulte K., Carbon nanotube-based composites, Compr.Compos. Mater. II., 2017. 4(1):pp. 201-229.

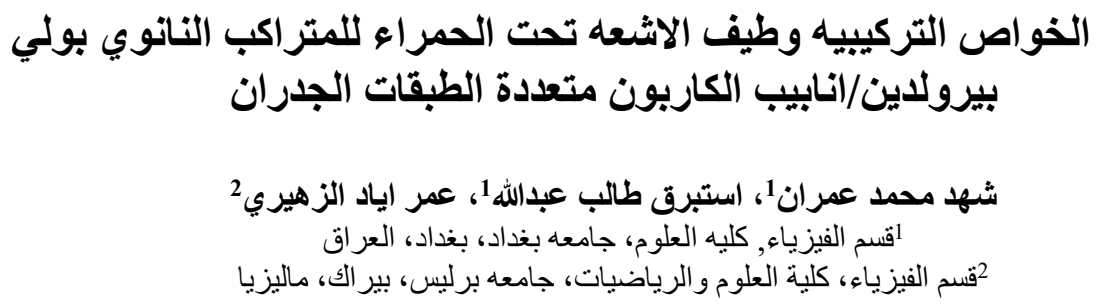

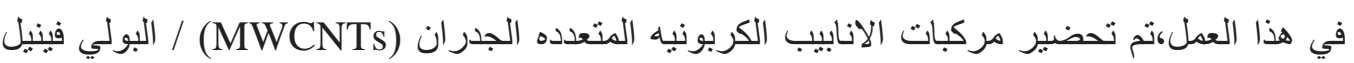

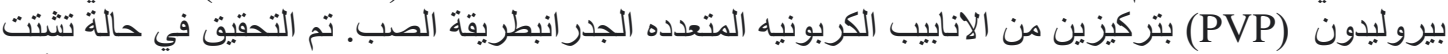

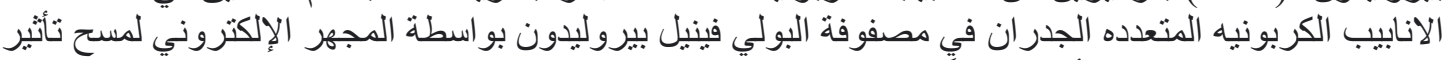

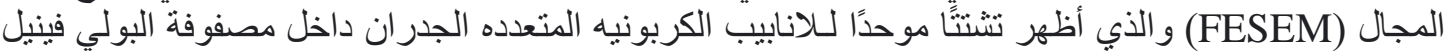

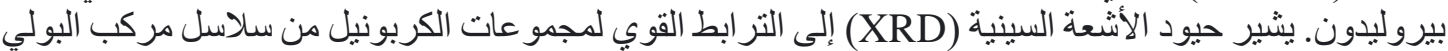

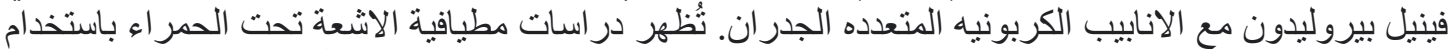

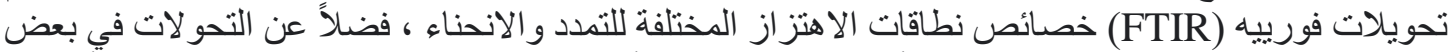

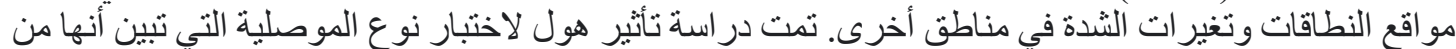

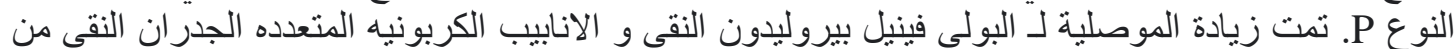

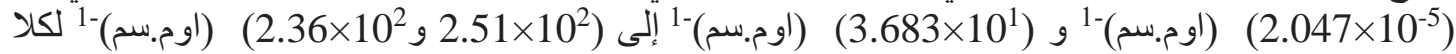
تر اكيز المركبات النانوية ، مما يشير إلى التحسين الذي تم إجراؤه للتوصيلية. 